\title{
The composite supply chain efficiency model: A case study of the Sishen-Saldanha supply chain
}

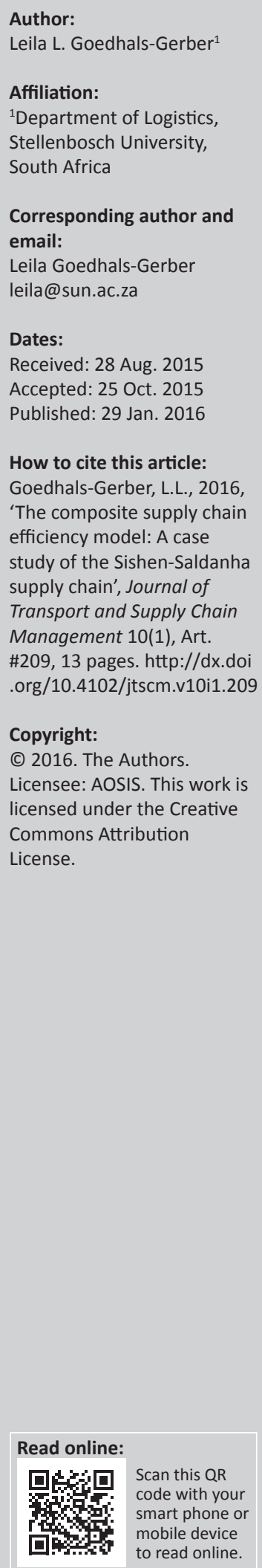

\begin{abstract}
As South Africa strives to be a major force in global markets, it is essential that South African supply chains achieve and maintain a competitive advantage. One approach to achieving this is to ensure that South African supply chains maximise their levels of efficiency. Consequently, the efficiency levels of South Africa's supply chains must be evaluated. The objective of this article is to propose a model that can assist South African industries in becoming internationally competitive by providing them with a tool for evaluating their levels of efficiency both as individual firms and as a component in an overall supply chain. The Composite Supply Chain Efficiency Model (CSCEM) was developed to measure supply chain efficiency across supply chains using variables identified as problem areas experienced by South African supply chains. The CSCEM is tested in this article using the Sishen-Saldanda iron ore supply chain as a case study. The results indicate that all three links or nodes along the Sishen-Saldanha iron ore supply chain performed well. The average efficiency of the rail leg was $97.34 \%$, while the average efficiency of the mine and the port were $97 \%$ and $95.44 \%$, respectively. The results also show that the CSCEM can be used by South African firms to measure their levels of supply chain efficiency. This article concludes with the benefits of the CSCEM.
\end{abstract}

\section{Introduction}

South Africa is a developing country with good economic development and rapid growth and forms part of the BRICS (Brazil, Russia, India, China and South Africa) countries (Chiu 2014). It is one of South Africa's goals to become a key player in global trade; however, South Africa has a number of hurdles to overcome before it reaches its goal. South Africa's total exports have only grown by $0.6 \%$ a year in real terms since 2005, whilst its BRIC counterparts have been growing rapidly (The World Bank 2014). Growth in South Africa's exports of non-minerals and services are also lagging behind BRIC partners, whilst the volumes of minerals exported from South Africa remain virtually unchanged. According to The World Bank (2014), the majority of South African exports are concentrated in a few super firms that ship products to countries around the world. Approximately 1000 companies generate 93\% of all of South Africa's exports. The remainder of South Africa's 20000 exporting firms export products in small amounts and make up the residual $7 \%$. In addition, these mega companies are losing impetus because they are creating fewer new products and not expanding into new markets (The World Bank 2014).

In addition, South Africa is facing socio-economic problems. South Africa is struggling with high levels of unemployment, which result in high levels of poverty (Everatt 2004; Statistics South Africa 2015). In addition, its workforce lacks skills, which intensifies the problem (Mkhwanazi 2012). Existing transport infrastructure is insufficient and is utilised at sub-optimal levels (Department of Government Communications and Information Systems 2015). These factors, along with numerous others, are hindering the country's growth. Furthermore, logistics have been identified by the South African government in the Accelerated and Shared-Growth Initiative of South Africa (ASGISA) as a potential hurdle that may limit future growth in the country (Ittmann 2007).

The growth and development of South Africa's economy and the subsequent welfare of its citizens are correlated with the country's trade levels (Nkomo 2005). More than 95\% of South Africa's trade volume takes place via deep-sea transport (Chasomeris 2005; Z. Christians [Cape Town] pers. interview, February 2015). In addition, a number of export industries are dependent on imported inputs, so efficient import supply chains also play an important role in South Africa's ability to compete globally (Page 2012). Therefore, to be a major force in global trade, it is important that existing maritime supply chains ${ }^{1}$ to and from South Africa function as efficiently as possible and new efficient supply chains are developed.

1.A maritime supply chain is defined for the purposes of this article as a supply chain that has a deep-sea leg.

Note: This article is partially based on the author's thesis of the degree of Doctor of Philosophy in Logistics Management at the Department of Logistics, Stellenbosch University, South Africa, with promoter Prof. W.J. Pienaar, received March 2010, available here: http://scholar.su.ac.za/bitstreamhandle/10019.1/4002/Gerber,+L.L.G.pdf.txt?sequence=2 
The importance of supply chains operating efficiently is a concept that has been understood and researched by governments and industries competing with South Africa for a number of years. However, South Africa's government has only realised the importance of efficient supply chains since the turn of the century (Neill 2003).

The Composite Supply Chain Efficiency Model (CSCEM) introduced in this article proposes a set of guidelines that can assist South African industries in becoming internationally competitive. The CSCEM was developed by the author. It is a tool that can be used to evaluate a firm's level of efficiency both as an individual firm and as a component in an overall supply chain. The CSCEM is tested in this article by applying it to the Sishen-Saldanha iron ore supply chain. The results from the case study indicate that the CSCEM can be used by South African firms to pinpoint the processes that need amendments to improve their overall supply chain efficiency.

The next section provides the problem statement and objectives investigated in the article. The literature review defines the terms 'supply chains' and 'supply chain management'. It describes the challenges facing the measurement of supply chain efficiency and the benefits that can be achieved by firms that measure their levels of supply chain efficiency. It also provides an overview of existing models for measuring overall supply chain performance and introduces the mathematical technique used in the CSCEM, namely Data Envelopment Analysis (DEA). The literature review ends with a brief summary of the Sishen-Saldanha iron ore supply chain. The steps taken in the construction of the CSCEM are discussed as well as the methods used to verify and validate the CSCEM. A case study of the SishenSaldanha iron ore supply chain is used to test the robustness of the CSCEM. This article concludes with the benefits of the CSCEM.

\section{Problem statement}

Trade liberalisation has led to greater levels of competition throughout the international commodity and service markets as a result of (amongst other things) the globalisation of businesses, an increase in product variety, increasing complexity of supply networks, and the shortening of product life-cycles. Increased levels of competition globally means that supply chains as a whole need to be as efficient as possible in order to be successful (Naslund \& Williamson 2010).

It is no longer sufficient for link providers to focus only on individual elements of the supply chain. They now need to take the efficiency of the entire chain into account (Holmberg 2000). For South African firms to be competitive in the global market, they have to be able to adapt to rapidly intensifying customer forces and changing customer needs. Firms that understand the full impact of logistics on supply chain management use as many opportunities as possible to apply enhancements to their structures and strategies to improve their overall efficiency (Dooley 2005).
The main objective of this article is to propose a model that can help South African industries improve their competitiveness in global markets. This article introduces the CSCEM, which can be used to evaluate the level of efficiency of South African industries both as individual firms and as a component in an overall supply chain. The CSCEM is tested in this article by using a case study of the Sishen-Saldanha iron ore supply chain.

\section{Literature review}

\section{Defining supply chains and supply chain management}

A supply chain is defined by Joseph and Mohapatra (2009:468) as 'a chain or progression beginning with raw materials and ending with the sale of the finished product or service'. The links in the supply chain fulfil various functions that contribute, to a greater or lesser extent, to the success of the chain. Any link in the chain that does not perform optimally can reduce the overall efficiency of the entire supply chain (Chopra \& Sodhi 2014).

In the global economy, the main focus of market competition is not only between products but between the supply chains delivering the products. As the satisfaction of the consumer is the ultimate test of success of the whole chain, the effective management of the link processes is crucial (Trkman, Indihar Stemberger \& Jaklic 2005). A major task for ensuring that a supply chain operates efficiently is thus the management of the entire chain.

Supply chain management is defined by the Council for Supply Chain Management Professionals (2015) as:

encompassing the planning and management of all activities involved in sourcing and procurement, conversion, and all logistics management activities. Importantly, it also includes coordination and collaboration with channel partners, which can be suppliers, intermediaries, third-party service providers, and customers. In essence, supply chain management integrates supply and demand management within and across companies. (n.p.)

According to Davis (1993), effective supply chain management can be achieved by optimising all the activities throughout the supply chain, and it plays an important role in providing a competitive business advantage. Consequently, a discussion has ensued as to whether all functions should be provided by one organisation or whether each function should be provided by a specialist in the specific field. One argument is that the separation of supply chain activities among different companies enables specialisation and economies of scale (Trkman et al. 2005), while the others argue that if a supply chain consists of more than one organisation, the companies often tend to optimise their own performance, disregarding the benefits of a supply chain as a whole (Awad \& Nassar 2010). The situation is further complicated if the various parties involved in the supply chain have different objectives.

A closer look at the discussion shows that the two sides may be in favour of the same approach but are arguing for it from a 
different angle. The central theme is that link providers need to focus on the entire process and not on individual elements. Link providers should thus strive to promote maximum efficiency throughout the entire chain rather than concentrate on their own goals (Naslund \& Williamson 2010). Therefore, supply chain managers that operate a single, integrated chain have an advantage in the competition between supply chains (Sadler 2007). No supply chain in which autonomous links optimise their performance can achieve maximum efficiency. In contrast, a supply chain that is operating at sub-optimal efficiency reduces the market penetration of the product it carries (Sadler 2007).

Supply chain visibility (defined as 'the awareness of, and control over, specific information related to product orders and physical shipments, including transport and logistics activities, and the statuses of events and milestones that occur prior to and in-transit' [Heaney 2013:2]) and supply chain integration (defined as 'an integrative philosophy to manage the total flow of a distribution channel from the supplier to the ultimate user'. [Cooper \& Ellram 1990:1]) greatly increase the ability of managers to pinpoint the weaknesses in the chain in order to effect improvements. Integrating the links of the supply chain into a holistic, efficiently functioning system improves the flow of both products and information in the organisation (Heaney 2013). That leads to a more efficient supply chain. Thus, maximising efficiency should be the overall aim, whether a supply chain comprises links operated by several role players or is under the control of a single management (Braithwaite 2005).

\section{Measuring supply chain efficiency}

Efficient management of a supply chain has been increasingly recognised as a key factor in differentiating product and service offerings and gaining competitive advantage for firms (Christopher 1998). It demands the close integration of internal functions within a firm and efficient linkages with the external operations of channel members in the chain (Lee 2000). It is also essential that supply chains do not remain static, but rather evolve continuously based on the changing market and customer needs (Little 1999).

For the purpose of this article 'supply chain efficiency' will be defined as the economy in resource utilisation based on specific criterion while products are moved from one place to another, in the course of which movement the products may be changed through processing.

The need to improve efficiency in a supply chain has led to the development of models and methods to measure supply chain efficiency. These models can be used to evaluate the levels of performance along supply chains and help managers identify weaknesses in order to improve the overall functioning of the chains.

To raise the level of efficiency, it is necessary to be able to measure that level throughout all the links along the supply chain (Gunasekaran, Patel \& McGaughey 2004). Spekman,
Salmonds and Kamauff (1994) argue that the challenge for measurement is that chain efficiency cannot be measured by single transactions but only through the evaluation of the performances of all the link service providers along the entire supply chain. Therefore, when devising how to measure supply chain efficiency, it is important to choose a method that takes all relevant factors into account.

Langfield-Smith and Smith (2005) and Cuthbertson and Piotrowicz (2011) highlight a second obstacle to the measure of supply chain efficiency; namely, that performance measures are not always used in a balanced way that reflects all aspects of the supply chain. Frequently, one measurement or another is over-emphasised, leading to inaccurate measurements or sub-optimisation of the supply chain. Little (1999) argues that this risk increases if no single body overseas the entire chain. Thus, when measuring the supply chain, the method devised must evaluate each link in terms of the correct ratio of importance to the overall output of the supply chain.

Because firms often deal in different product lines, it is important that a supply chain exists for each and every commodity (Sadler 2007). Nigel Wright Group (2015) point out that supply chains from different sectors (of industry) have different characteristics that can vary within those sectors. Thus, supply chain design must clearly be tailored to both the specific industry and the individual circumstances of each business (Childerhouse \& Towill 2000). It is also important that every service provider in the supply chain use the same method for measuring efficiency to provide meaningful results. Therefore, when choosing a tool for measuring supply chain efficiency, it is important that firms choose one that can be applied to all of their functions (Little 1999).

Another factor that must be taken into consideration when measuring supply chain efficiency is the strategy for the growth of the supply chain. Supply chains that work well with current volumes may become problematic in the future if flexibility, responsiveness and scalability have not been designed into the system (Barloworld Logistics 2005). Thus, it is important to plan proactively rather than reactively, to ensure that supply chains maintain their efficiency, lest they lose opportunities.

\section{Existing models for measuring overall supply chain performance}

A common challenge facing many firms is that a supply chain is often composed of independent business units and legal entities with separate owners and managers, each with differing business goals and objectives (Chandra \& Grabis 2007). However, there is sufficient evidence to support the notion that both private and public firms can benefit from the integration and synchronization of cross-enterprise processes, such that various firms cooperate to optimise the supply chain (van der Laan 2010). Consequently, numerous efforts have been made to develop methods for measuring system-wide supply chain performance (Davis \& Spekman 2004). 
Three of the best known proposals for co-ordinated chainwide performance measurement are (Davis \& Spekman 2004):

- The Supply Chain Operations Reference (SCOR) model.

- The Supply Chain Performance Scorecard developed by the Performance Measurement Group (PMG).

- $\quad$ The Balanced Scorecard (BSC) for SCM.

TheSCOR model was developed by the Supply Chain Council. It is a strategic planning tool that assists senior managers to simplify the complexity of supply chain management (Huan, Sheoran \& Wang 2004). The aim of the SCOR model is to provide a standardized method of measuring supply chain performance and use a common set of metrics to benchmark against other organisations (Forbes.com 2006).

The SCOR model starts by measuring the current state of the process being examined. This information is then ultilised to determine the desired future state of the process. Subsequently, the operational performance has to be quantified and compared to that of similar companies, to determine internal targets based on 'best-in-class' results. Finally, best practice analysis is performed to identify management practices and software solutions that can result in 'best-in-class' performance. The main goal of SCOR is the description, measurement and analysis of supply chain configurations (Kussing 2009).

SCOR is based on six distinct management processes namely, Plan, Source, Make, Deliver, Return and Enable. It also facilitates inter and intra supply chain collaboration and horizontal process integration, by explaining the relationships between processes (i.e. Plan-Source, PlanMake) (Badr \& Stephan 2007). In addition, the SCOR model is beneficial for entering data to analyse various configuration options better, for example Make-To-Order and Make-ToStock. The SCOR model makes this possible by describing, measuring, and evaluating the supply chain. It also supports strategic planning and encourages continual improvement of the chain.

Although the SCOR model has a number of benefits, according to Wong and Wong (2008), SCOR fails to address the issue of integration synchronization. One of the findings highlighted by Samuel, Sunl and Wang (2004) was that:

although the SCOR model provides a common supplychain framework, standard terminology, common metrics associated benchmarks and best practices, the approach on the utilization of SCOR seems to be rather rigid and needs further enhancement. (p. 28)

As supply chains become increasingly complex and levels of competition between firms continue to rise, firms are looking for a way to achieve or maintain a competitive advantage. One solution to the problem is a dynamic performance measurement that is able to evaluate a variety of different variables and scenarios. However, SCOR does not currently have the ability to meet all those needs (Samuel et al. 2004).
According to Wong and Wong (2008), SCOR needs a network modelling tool to support the change management decision. In addition, SCOR needs to meet a firm's need to address supply chain benchmarking from a holistic approach. Thus, in order for the SCOR model to more accurately evaluate integrated supply chains, it is important to include some change management. To date, SCOR has only been using deterministic performance metrics, measures that managers can control and determine accurately (Wong \& Wong 2008). However, in an integrated supply chain, the levels of the chain become more complicated, and managers have to be accountable for various performance measures (Samuel et al. 2004).

The SCOR model is currently used as cross-industry standard for supply chain management, both internationally and in South Africa. Although it can be used successfully to measure supply chain performance, it does not measure supply chain efficiency. The CSCEM introduced in this article can measure supply chain efficiency.

The second model commonly used to measure supply chain performance is the Supply Chain Performance Scorecard. The Supply Chain Performance Scorecard was developed by the PMG in 1994. Four broad areas of performance measurement are addressed, namely, customer satisfaction, cost, time and assets (Davis \& Spekman 2004).

The scorecard originally contained eight measurements, but has evolved into a balanced set of four measurements including two customer-facing (delivery performance to commit and upside production flexibility) and two internallyfacing metrics (cash-to-cash cycle time and net asset turns) (Davis \& Spekman 2004). The Supply Chain Performance Model is not able to measure supply chain efficiency.

The third model often used to measure supply chain performance is the BSC method, which was developed by Kaplan and Norton during the early nineties. The BSC is a management system that enables organisations to identify their goals and then develop a strategy that helps meet the goals. It provides feedback around both the internal business processes and external outcomes to improve strategic performance and results. Subsequently, managers are able to identify all the important aspects of the business in order to minimise the tendency to improve one area of the business at the expense of another (Abu-Suleiman, Boardman \& Priest 2004). However, the BSC has a weakness in that it does not take competitors into account (Neely, Gregory \& Platts 1995). The CSCEM introduced in this article includes the benefits of the BSC method, i.e. it ensures that one link or node in the supply chain is not improved at the expense of another, however, it also takes competitors into account.

\section{Data envelopment analysis}

DEA was first introduced by Charnes, Cooper and Rhodes (1978) as a linear programming (LP)-based methodology for performing the analysis of how efficiently a firm operates 
(Wong \& Wong 2007). DEA is a data-oriented approach for evaluating the performance of a set of peer entities called Decision Making Units (DMU), which have the ability to convert multiple inputs into multiple outputs (Cooper, Seiford \& Zhu 2004). It is a nonparametric approach to frontier estimation, i.e. DEA does not rely on the definition of the specific role that the variables perform to specify the relationships or trade-offs among the performance measures in the calculation of efficiency. Moreover, it utilises the concept of efficient frontier as an empirical benchmark. (Mathematically, the efficient frontier 'is the intersection of the set of portfolios with minimum variance and the set of portfolios with maximum return' (Chen et al. 2008). It is defined by Granite Financial Group (2009) as:

a statistical result from the analysis of the risk and return for a given set of assets that indicates the balance of assets that may, under certain assumptions, achieve the best return for a given level of risk. (n.p.)

These advantages of DEA enable managers to evaluate any measures efficiently as they do not need to find any relationship that relates to them (Wong \& Wong 2007).

DEA is an extreme point method and compares each variable with only the 'best' variable (University of Phoenix 1996). Because it only requires a few assumptions, DEA can be used in cases that have been resistant to other approaches, because of the complex (often unknown) nature of the relationships between the multiple inputs and multiple outputs involved in the DMUs (Cooper et al. 2004).

The basis of DEA is in finding the optimal virtual variable for each real variable. If the virtual variable is better than the original variable, because it either makes more output with the same input or the same output with less input, then the original variable is inefficient (University of Phoenix 1996).

DEA does not require assigned numeric weights or modelling preferences for analysis. However, it is possible to introduce these numeric weights if the information is available, and it is believed to be helpful. The DEA model automatically computes weights that give the highest possible efficiency score to a DMU whilst keeping the efficiency scores of all DMUs less than or equal to one under the same set of weights (Wong \& Wong 2007). This helps to prevent the bias of different analysts from influencing the selection of the criteria used in the analysis (Wong \& Wong 2007).

The main limitation of DEA is that the efficiency measured is a relative efficiency. DEA determines the efficiency of different units within the supply chain relative to each other and rather than to a set target value. This can be misleading to managers and stakeholders (Agami, Saleh \& Rasmy 2012). In addition, DEA requires large amounts of data to provide meaningful results, and it can be difficult to gain access to enough data to measure the efficiency of a supply chain.

\section{The Sishen-Saldanha iron ore supply chain}

The origin of the Sishen-Saldanha iron ore supply chain dates back to 1953 when Iron and Steel Corporation (Iscor) now known as ArcelorMittal started mining iron ore near Sishen in the northern Cape. Due to the depletion of some of South Africa's gold reserves in the 1960s, mines were compelled to find alternative mineral resources. After the discovery of a 4000-Mt deposit of high grade iron near Sishen, the feasibility of a new, large-scale iron ore export project was explored. These investigations led to Saldanha Bay being chosen as the best port of export for the ore. The railway line connecting the ore-mines with the port was subsequently built (Truter 2004).

Construction on the railway line started on 01 June 1973 and the first ore train arrived at the Port of Saldanha on 14 May 1976. On 27 September of the same year, the first ore carrier left the Port of Saldanha, bound for Europe (Truter 2004). The supply chain has subsequently been acquired and developed by Transnet Freight Rail. It is now known as Orex.

The major links and nodes in the Sishen-Saldanha iron ore supply chain are (N. Ramchand [Stellenbosch] pers. interview, 13 February 2007):

- the mines (Kumba Resources Ltd and Associated Manganese [ASSMANG] iron ore mine)

- vehicles carrying the products in the mine (often dieselelectric trucks or trains)

- loading apparatus to build stockpiles

- benefication plant at the mine (e.g. washing plant)

- the railway line (Orex)

- the storage and handling equipment

- the Port of Saldanha (Transnet National Ports Authority [TNPA], Transnet Port Terminals [TPT] and Kumba Port Operations Saldanha)

- the ship

- the documentation required throughout the supply chain.

Each element of the supply chain plays a significant role in determining the overall efficiency of the supply chain. The supply chain is only as efficient as its weakest link. Therefore, steps must be taken to ensure maximum efficiency not only at each link or node, but also throughout the entire supply chain (Sadler 2007).

\section{Research method and design}

The primary research was interviews that were conducted with experts in the field (the respondents held either managerial, director or general manager positions) to determine the various concerns that exist along South African supply chains and to develop a better understanding of the workings of South African supply chains. The interviews were also used to obtain independent views on the usefulness of the present modelling systems used along supply chains in South Africa, as well as to acquire impartial views on the efficiency of South African supply chains as a whole. Participants were identified by dividing South Africa's supply chains into different categories according to product characteristics, that is, bulk commodities, 
containerised goods, fast moving consumer goods, the textile industry, the automotive industry and perishable products. Senior executives from 10 leading firms from each category (60 in total) were contacted and asked questions about the factors that affect their companies. Factors that influence supply chain efficiency in South Africa, as identified through personal interviews, are:

- the ratio of idle time to productive time

- throughput, lead time and utilisation of the supply chain capacity

- infrastructure availability and utilisation

- low transport productivity

- method of freight handling

- interface arrangements

- labour competency

- communication throughout the supply chain

- incidence of damage to goods and pilferage

- imbalances in cargo flows

- documentation required

- customer co-operation.

After identifying the main factors that influence supply chain efficiency in South Africa, the factors had to be incorporated into the CSCEM. Supply Chain Efficiency Measures or Logistics Performance Measures are used to classify the above factors in the CSCEM. Three parameters were chosen to determine efficiency across a supply chain, namely: reliability, speed and cost. These three parameters were chosen under the guidance of the experts that were interviewed. This also includes determining whether or not these factors are considered to be inputs or outputs (i.e. consumables or deliverables) of the supply chain. It is possible that factors selected for the inclusion in the CSCEM can differ from supply chain to supply chain.

The next step in the CSCEM involved subdividing a supply chain into links and nodes. Information was collected about various performance measures that could potentially be used to calculate the performance of each of the five links and nodes in terms of reliability, speed and cost. Measures were also identified that could be used to calculate the influence that these factors have on the overall efficiency of a supply chain. Generic links and nodes identified for the CSCEM are: sources or suppliers, points of production, transportation links, points of storage and transhipment and markets or customers.

Next, formulae were used to convert the factors that influence supply chain efficiency into measurements of efficiency within each link or node in the supply chain in terms of reliability efficiency, speed efficiency, and cost efficiency. The calculations indicate how the individual firms along the supply chain are performing.

Finally, DEA is used to take the information gathered in the previous step to compare the reliability efficiency, speed efficiency and cost efficiency across the individual links or nodes in the supply chain with similar links or nodes of other supply chains. This is used to determine the 'frontier' or most efficient supply chain, which can consist of a combination of various different supply chains. Finally, each individual supply chain is compared with the frontier to determine how efficient it is and where bottlenecks occur. Figure 1 is a graphic representation of how the CSCEM was developed.

Historical data was collected from the Sishen-Saldanha iron ore supply chain to test the CSCEM. Six years of historical data was collected from the mine, 8 years of historical data was collected from the rail transport operator, and 9 years of historical data was collected from the port. The data collected was insufficient to obtain meaningful results, because for the method used in the CSCEM (namely DEA) the number of input and output variables need to be less than half of the number of DMUs, which in this article represents 1 year for either the mine, rail transport operator or port. In order to make the model as inclusive as possible, 14 input variables and four output variables (18 variables in total) were used. This meant that for the CSCEM to provide significant results, at least 36 years of historical data was required from each link or node in the supply chain.

Due to the fact that the example used in this article is for explanatory purposes only, (random) data was generated using the statistical program R 2.9 .2 (2009). The random data was generated from the original, real data sets using multivariate normal distribution. Since the data was generated using a recognised statistical method, it can be

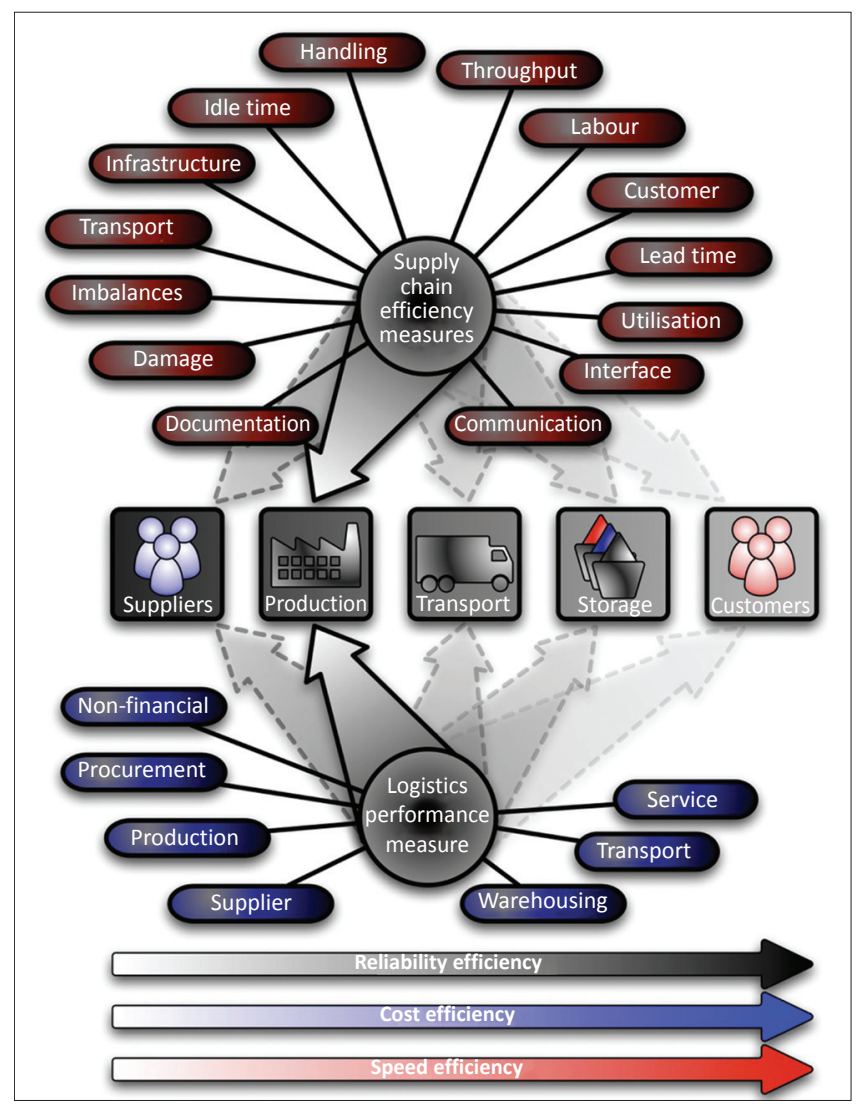

Source: Goedhals-Gerber, L.L., 2010, The Measurement of Supply Chain Efficiency: Theoretical Considerations and Practical Criteria, PhD dissertation, Stellenbosch University, Stellenbosch FIGURE 1: Graphic representation of the composite supply chain efficiency model. 
assumed that the data meets the necessary requirements for testing the validity of the CSCEM.

The CSCEM can be used on a range of diverse supply chains due to its generic nature. It is possible to make changes to the input factors selected, by either including additional factors or removing some of the factors included, should a firm want to make changes. Different variables can be used to calculate its efficiency, depending of the focus on the supply chain under investigation. For example, speed is an important factor in a supply chain carrying perishable products and, therefore, variables will be included to calculate the efficiency of the supply chain in terms of speed. However, for a supply chain carrying low-value bulk products, speed is not important and can be left out of the calculation.

No two supply chains are exactly the same and therefore, it is not possible to compare supply chains that are exactly the same. However, benefits are still achieved by comparing supply chains with similar characteristics. For supply chains to be considered to have similar characteristics, it is important that they have three common factors. First, they must have the same drivers. This means that they must focus on the same focal points (in terms of this article, they must arrange reliability efficiency, cost efficiency and speed efficiency in the same order of importance). Second, geographical context must be the same, i.e. they must all be either local supply chains or all international supply chains. Finally, the supply chains must handle goods with similar commodity characteristics. For example, they all handle perishable products or they all handle dry bulk goods.

\section{Model construction}

The final step of the CSCEM uses DEA, a mathematical programming technique that calculates the relative efficiencies of multiple DMUs based on multiple inputs and outputs (Wong \& Wong 2007). DEA has been demonstrated to be a suitable mathematical method for measuring efficiency in a variety of academic literature (Bell \& Morey 1995; Seiford 1994; Talluri \& Sarkis 2001; Wong \& Wong 2007, 2008). DEA measures the relative efficiency of each DMU in comparison with all other DMUs. It, therefore, has the ability to establish the effect that the DMU has on the overall efficiency of the supply chain under investigation. The efficiency score of a specific DMU is defined as the weighted sum of outputs divided by the weighted sum of inputs (for which weights need to be assigned). DEA automatically calculates weights that provide the highest possible relative efficiency score to a DMU. At the same time, DEA keeps the efficiency scores of all DMUs less or equal to 1, under the same set of weights (Wong \& Wong 2007).

DEA is a form of LP. Therefore, one of the simplest ways of solving the problem is by writing it in its canonical form:

Maximize $z=\sum_{r=1}^{s} u_{r} y_{r j_{o}}$

[Eqn 1]
Subject to:

$\sum_{i=1}^{m} v_{i} x_{i j_{o}}=1$

$\sum_{r=1}^{s} u_{r} y_{r j}-\sum_{i=1}^{m} v_{i} x_{i j} \leq 0 \quad j=1,2, \ldots, n$

$u_{r} \geq \varepsilon, \quad r=1,2, \ldots, s \quad v_{i} \geq \varepsilon \quad i=1,2, \ldots, m$

In LP, it is possible for DEA to formulate a partner linear program or LP using the same data. The solution to either the original LP (the primal) or the partner (the dual) is the same. According to Emrouznejad (2001), the dual model is constructed by assigning a variable (dual variable) to each constraint in the primal model and constructing a new model based on these variables.

The main reason for using a dual to solve a DEA model is that the primal model has $n+s+m+1$ constraints, whilst the dual model has $s+m$ constraints. As $n$, the number of units, is usually considerably larger than $s+m$, the number of inputs and outputs, the primal model will have considerably more constraints than the dual model (Emrouznejad 2001). For LPs in general, the more constraints there are, the more difficult it is to solve the problem. The dual for equation 1 can be given as follows:

$\theta^{*}=$ Minimise $\theta$

[Eqn 2]

Subject to:

$\sum_{j=1}^{n} \lambda_{j} x_{i j} \leq \theta x_{i j_{0}} \quad i=1,2, \ldots, m ;$

$\sum_{j=1}^{n} \lambda_{j} y_{r j} \geq y_{r j_{0}} \quad r=1,2, \ldots, s$

$\lambda_{j} \geq 0 \quad j=1,2, \ldots, n$

By virtue of the dual theorem of $\mathrm{LP}, \mathrm{z}^{*}=\theta^{*}$. Therefore, either equation 1 or equation 2 can be used to calculate the solution. The optimal solution, $\theta^{*}$, returns an efficiency score for a particular DMU. The process can be repeated for each DMUjo. DMUs for which $\theta^{*}<1$ are classified as inefficient, while DMUs for which $\theta^{*}=1$ are classified as boundary points.

Some boundary points may be classified as 'weakly efficient' because they include non-zero slacks (non-zero slack values represent a substantial amount of inefficiency) (Morita, Hirokawa \& Zhu 2005). This may result in lower confidence levels in the solutions identified because alternative optima may have non-zero slacks in some solutions, but not in others. Input slacks indicate the surplus number of inputs that are being utilised by $\mathrm{DMU}_{\mathrm{jo}}$ and the output slacks represent the shortfalls in the outputs of $\mathrm{DMU}_{\mathrm{jo}}$. Therefore, the slacks can be used by managers to identify bottlenecks in supply chains. This problem can be avoided by rewriting equation 2 to include the slacks which are taken to their maximal values. This equation can be written as follows:

Maximise $=\sum_{i=1}^{m} S_{i}{ }^{-}+\sum_{r=1}^{s} S_{r}$

[Eqn 3] 
Subject to:

$\sum_{j=1}^{n} \lambda_{j} x_{i j}+s_{i}^{-}=\theta^{*} x_{i j_{0}} \quad i=1,2, \ldots, m ;$

$\sum_{j=1}^{n} \lambda_{j} y_{r j}-s_{r}^{+}=y_{r j_{0}} \quad r=1,2, \ldots, s ;$

$\lambda_{j}, s_{i}^{-}, s_{r}^{+} \geq 0 \quad \nabla i, j, r$

where the choices of $s_{i}^{-}$and $s_{r}{ }^{+}$do not affect the optimal $\theta^{*}$ which is determined from equation 2.

According to the definition for DEA efficiency by Cooper et al. (2004) the performance of $\mathrm{DMU}_{\text {jo }}$ is only fully (100\%) efficient if and only if both (1) $\theta^{*}=1$ and (2) all slacks $s_{i}^{-}=s_{r}^{+}=0$. The definition for weakly DEA efficient states that the performance of $\mathrm{DMU}_{\mathrm{jo}}$ is weakly efficient if and only if both (1) $\theta^{*}=1$ and (2) $\mathrm{s}_{\mathrm{i}}^{-} \neq 0$ and/or $\mathrm{s}_{\mathrm{r}}{ }^{+} \neq 0$ for some $i$ and $r$ in some alternate optima (Cooper et al. 2004).

The variable $\theta$ gives the technical efficiency, which is what the model is trying to calculate and $s_{i}^{-}$and $s_{r}^{+}$are the input and output slacks, respectively. When $\mathrm{DMU}_{\mathrm{jo}}$ is proven as either strongly or weakly DEA efficient, then no further calculations are required. However, when $\mathrm{DMU}_{\mathrm{jo}}$ is identified as inefficient, appropriate adjustments (equations 4 and 5) can be applied to the inputs and outputs to make $\mathrm{DMU}_{\mathrm{jo}}$ more efficient:

$x_{i j_{o}}^{\prime}=\theta^{*} x_{i j_{o}}-s_{i}^{-*} \quad i=1,2, \ldots, m$

[Eqn 4]

$y_{r j_{o}}^{\prime}=y_{r j_{o}}+s_{r}^{+*} \quad r=1,2, \ldots, s$

[Eqn 5]

The dual model of the above formulation (also known as the envelopment model) has the ability to identify possible solutions to improve the efficiency of a DMU. As a result, it highlights ways in which managers can make improvements to the supply chain. An additional convexity constraint:

$\sum_{j=1}^{n} \lambda_{j}=1$

can be added to equation 3 to yield a measure of the pure technical efficiency if the constant return-to-scale (Banker, Charnes \& Cooper 1984) assumption does not apply, that is, there is not a constant ratio between inputs and outputs. The above model (equation 3) is used to calculate the technical efficiency of a supply chain and can therefore be referred to as the technical efficiency model.

The next step in developing a model to measure supply chain efficiency across an entire supply chain is to minimise costs along the supply chain without reducing the level of outputs achieved. This can be calculated by the cost efficiency model shown below:

Minimise $\sum_{i=1}^{m} c_{i j_{o}} x_{i}$

[Eqn 6]
Subject to:

$x_{i} \geq \sum_{j=1}^{n} x_{i j} \lambda_{j} \quad i=1,2, \ldots, m$

$y_{r j_{0}} \leq \sum_{j=1}^{n} y_{r j} \lambda_{j} \quad r=1,2, \ldots, s$

where $c_{i j o}$ is the unit cost of the input $i$ of $\mathrm{DMU}_{\mathrm{jo}}$ which may vary from one DMU to another. The total cost efficiency (CE) of the $\mathrm{DMU}_{\mathrm{jo}}$ would be calculated as:

$\mathrm{CE}=\frac{c_{i j_{o}}^{\prime} x_{i j_{o}}^{\prime}}{c_{i j_{o}}^{\prime} x_{i j_{o}}}$

Equation 7 above can be described as the ratio of minimum cost to the observed cost. It is then possible to calculate the allocative efficiency (AE) by dividing the cost efficiency by the technical efficiency (TE) as shown in equation 8 :

$\mathrm{AE}=\frac{\mathrm{CE}}{\mathrm{TE}}$

[Eqn 8]

The AE measure includes slacks which reflect an inappropriate input mix (Ferrier \& Lovell 1990). This information, together with the opportunity cost calculated, provides important information regarding the technical and cost efficiency along a supply chain. This information can be helpful to managers by providing reliable criteria on which to base decisions for allocating resources, and identifying ways to ensure that the supply chain adjusts to the changing needs of the customers.

\section{Model verification and validation}

The first three steps of the CSCEM are validated and verified by the fact that they can be replaced by the BSC method, which is implemented by many firms around the world. Data measured by either the first three steps of the CSCEM or the BSC method will give similar results.

According to Wong and Wong (2007), DEA is a suitable tool for measuring supply chain efficiency because it can handle multiple inputs and outputs and does not require unrealistic assumptions about the variables that typically characterise supply chain optimisation models. Numerous sources of literature verify the use of DEA in measuring efficiency (Bell \& Morey 1995; Seiford 1994; Talluri \& Sarkis 2001).

According to the literature and experts in the field, DEA is mainly used for two different evaluation purposes. Firstly, it can be used to compare the performance of one firm or one department with another, assuming all firms or departments have similar strategic goals and objectives (Wong \& Wong 2008). Secondly, DEA can be used to compare the efficiency of a department or firm with historical data to identify how it has performed over time.

DEA has the ability to compare variables with several different units and deliver meaningful results. When DEA 
is used to compare competing supply chains (with similar characteristics), the results represent the leading supply chain and an indication of how the other supply chains compare. It is important to note that the leading supply chain identified is not necessarily an actual working supply chain. The leading supply chain can be made up of a mixture of links or nodes from different supply chains. When DEA is used to compare one supply chain over time, that is, with historical data, it shows how the efficiency of the supply chain has improved or deteriorated over time.

\section{Example}

To validate the robustness of the CSCEM, it was applied to the iron ore supply chain from Sishen to Saldanha.

The example used is an input-oriented model with variable returns to scale. An input-oriented model was developed to determine whether the supply chain is achieving the current level of outputs given the minimum level of inputs. If so, the supply chain can be considered efficient. However, if it is possible to decrease the inputs while retaining the required level of outputs, then the supply chain is operating inefficiently. Mines operate according to demand. Therefore, as the demand from customers rises, mines endeavour to increase their extraction. However, when demand remains unaffected, mines improve their efficiency levels by diminishing the resources needed to meet the output. Variable returns to scale is the best option to use, because various links and nodes in the supply chain may exhibit increasing, constant and decreasing returns to scale.

A variable in the CSCEM is categorised as an input if it is a ratio used to measure resources placed into the link or node or used in its operation to achieve an output or a result. A variable in the CSCEM is classified as an output if it is a ratio used to measure the work done by the link or node. The variables used in the CSCEM were placed into categories based on the appropriate link or node. They were then further divided into subcategories to measure the efficiency of the link or node in terms of reliability efficiency, cost efficiency and speed efficiency. All variables that were identified as being either utilised in the working of the supply chain or as having an impact on the working of the supply chain were classified as inputs, while all variables that were identified as a consequence of the supply chain were classified as outputs.

The main limitation of the CSCEM is that it requires large amounts of data to provide meaningful results. For DEA to provide meaningful results, the number of input and output variables needs to be less than half of the number of DMUs. In the case study, 14 input variables and four output variables (18 variables in total) were used. This meant that in order for the CSCEM to provide significant results, at least 36 years of historical data was required from each link or node in the supply chain.

\section{Analysis of results}

The study showed that the average efficiency of the rail leg for the Sishen-Saldanha iron ore supply chain was $97.34 \%$, while the average efficiency of the mine and the port were $97 \%$ and $95.44 \%$ respectively (Table 1 ). All three links or nodes performed well, which corresponds to the fact that the iron ore supply chain is one of the most efficient supply chains in South Africa.

The three areas on which the mine needs to focus to improve efficiency, identified through the research, are utilisation (in terms of reliability efficiency), system uptime (in terms of reliability efficiency) and communication (in terms of cost efficiency). The three areas of importance for the rail operator are throughput efficiency (in terms of reliability efficiency), cost per tonne of iron ore transported (in terms of cost efficiency) and communication (in terms of cost efficiency). The port needs to focus on infrastructure (in terms of cost efficiency), communication (in terms of reliability efficiency) and labour (in terms of cost efficiency).

The slack analysis depicted in Tables 2, 3 and 4 are presented in the virtual form. This allows the firm to identify exactly what variables are causing bottlenecks in the supply chain and, in so doing, allows them to take the necessary steps to improve their efficiency. For example, within DMU6 of the mine, i.e. year 6 , slack variable $\mathrm{s}^{-}$or system uptime is the biggest problem area for the mine, followed by slack variable $\mathrm{s}_{3}^{-}$(utilisation) and slack variable $\mathrm{s}_{8}^{-}$(labour in terms of cost).

\begin{tabular}{lc} 
TABLE 1: Efficiency analysis. & \\
\hline Nodes & Efficiency (\%) \\
\hline Mine & \\
DMU1 & 98.61 \\
DMU2 & 99.15 \\
DMU3 & 97.58 \\
DMU4 & 94.78 \\
DMU5 & 94.73 \\
DMU6 & 97.03 \\
Rail & \\
DMU1 & \\
DMU2 & 100.00 \\
DMU3 & 90.44 \\
DMU4 & 100.00 \\
DMU5 & 100.00 \\
DMU6 & 94.30 \\
DMU7 & 100.00 \\
DMU8 & 93.98 \\
Port & 100.00 \\
DMU1 & \\
DMU2 & 99.34 \\
DMU3 & 100.00 \\
DMU4 & 95.45 \\
DMU5 & 100.00 \\
DMU6 & 89.98 \\
DMU7 & 98.67 \\
DMU8 & 93.37 \\
DMU9 & 95.63 \\
\hline Soure: & 96.55 \\
\hline
\end{tabular}

Source: Goedhals-Gerber, L.L., 2010, The Measurement of Supply Chain Efficiency: Theoretical Considerations and Practical Criteria, PhD dissertation, Stellenbosch University, Stellenbosch 
TABLE 2: Mine node slacks analysis results.

\begin{tabular}{|c|c|c|c|c|c|c|c|c|c|}
\hline Measure & Variable & Slack & DMU1 & DMU2 & DMU3 & DMU4 & DMU5 & DMU7 & DMU9 \\
\hline Utilisation & V301 & $\mathrm{s}_{1}^{-}$ & 0.0 & 0.0 & 0.0 & 0.0 & 1.303 & 13.947 & 14.481 \\
\hline Idle time & V302 & $\mathrm{S}_{2}^{-}$ & 3.359 & 11.450 & 0.0 & 0.0 & 0.0 & 0.0 & 0.0 \\
\hline Communication & V303 & $\mathrm{S}_{3}^{-}$ & 14.685 & 7.574 & 32.918 & 28.638 & 17.015 & 15.497 & 27.081 \\
\hline Document errors & V304 & $\mathrm{S}_{4}^{-}$ & 3.227 & 15.141 & 4.591 & 0.482 & 0.0 & 10.128 & 8.283 \\
\hline Cost per ton & V305 & $\mathrm{S}_{5}^{-}$ & 3.765 & 0.0 & 15.273 & 0.0 & 9.208 & 0.0 & 12.43 \\
\hline Inventory carry cost & V306 & $\mathrm{S}_{6}^{-}$ & 0.0 & 1.264 & 4.926 & 0.0 & 28.914 & 0.224 & 0.0 \\
\hline Infrastructure cost & V307 & $\mathrm{S}_{7}^{-}$ & 19.763 & 53.325 & 38.384 & 3.802 & 29.689 & 16.571 & 23.401 \\
\hline Labour & V308 & $\mathrm{S}_{8}^{-}$ & 0.151 & 0.0 & 6.649 & 16.946 & 14.886 & 3.494 & 4.239 \\
\hline Commincation & V309 & $\mathrm{S}_{9}^{-}$ & 0.0 & 0.0 & 20.822 & 11.154 & 0.0 & 3.046 & 9.332 \\
\hline Port throughput & U301 & $\mathrm{s}_{1}^{+}$ & 0.0 & 0.0 & 0.0 & 0.0 & 11.29 & 14.708 & 1.061 \\
\hline Handling efficiency & U302 & $\mathrm{s}_{2}^{+}$ & 0.0 & 7.336 & 0.0 & 3.883 & 0.0 & 0.0 & 1.476 \\
\hline
\end{tabular}

Source: Goedhals-Gerber, L.L., 2010, The Measurement of Supply Chain Efficiency: Theoretical Considerations and Practical Criteria, PhD dissertation, Stellenbosch University, Stellenbosch

TABLE 3: Rail node slacks analysis results.

\begin{tabular}{|c|c|c|c|c|}
\hline Measure & Slack & DMU2 & DMU5 & DMU7 \\
\hline Variability (R) & $\mathrm{s}_{1}^{-}$ & 0 & 8.611 & 0 \\
\hline Utilisation (R) & $\mathrm{s}_{2}^{-}$ & 1.1 & 0 & 5.314 \\
\hline Idle time (R) & $\mathrm{S}_{3}^{-}$ & 1.473 & 2.445 & 0 \\
\hline Communication (R) & $\mathrm{s}_{4}^{-}$ & 26.139 & 11.314 & 32.182 \\
\hline Cost per ton (C) & $\mathrm{S}_{5}^{-}$ & 11.402 & 12.349 & 10.845 \\
\hline Infrastructure cost (C) & $\mathrm{S}_{6}^{-}$ & 13.634 & 4.529 & 14.913 \\
\hline Labour (C) & $\mathrm{s}_{7}^{-}$ & 9.378 & 0 & 4.943 \\
\hline Perfect shipments (R) & $\mathrm{s}_{1}^{+}$ & 0 & 0 & 0 \\
\hline Throughput efficiency (R) & $\mathrm{S}_{2}^{+}$ & 14.871 & 21.29 & 18.504 \\
\hline Transit time (S) & $\mathrm{S}_{3}^{+}$ & 0 & 0 & 0 \\
\hline Goods handling efficiency (S) & $\mathrm{S}_{4}^{+}$ & 18.559 & 7.144 & 5.134 \\
\hline
\end{tabular}

Source: Goedhals-Gerber, L.L., 2010, The Measurement of Supply Chain Efficiency: Theoretical Considerations and Practical Criteria, PhD dissertation, Stellenbosch University, Stellenbosch

Within DMU5 of the rail leg, slack variable $\mathrm{s}_{2}^{+}$(throughput efficiency in terms of reliability) is the main cause for concern followed by slack variable $\mathrm{s}^{-}$(cost per tonne) and slack variable $\mathrm{s}_{4}^{-}$(communication in terms of reliability). Within DMU2 of the port, slack variable $\mathrm{s}_{7}^{-}$(labour in terms of cost) is the biggest problem followed by slack variable $\mathrm{s}_{4}^{-}$ (documentation errors) and slack variable $\mathrm{s}_{2}^{-}$(idle time).

Comparison of the slack results for the historical data of the three links or nodes identifies the areas of concern within each link or node. Table 2 shows that, for the mine, improved efficiency must focus on the three areas of system uptime (in terms of reliability efficiency), utilisation (in terms of reliability efficiency) and communication (in terms of cost efficiency). Table 3 shows that the three areas of importance for the rail operator are communication (in terms of cost efficiency), throughput efficiency (in terms of reliability efficiency) and cost per tonne of iron ore transported (in terms of cost efficiency). Table 4 shows that the port needs to focus on infrastructure (in terms of cost efficiency), communication (in terms of reliability efficiency) and labour (in terms of cost efficiency).

The results obtained from the CSCEM were compared to results obtained by an independent company who used the BSC method to measure the efficiency of the Sishen-Saldanha supply chain. Due to confidentiality constraints, the results of the other study cannot be provided in this article. However, similar results were obtained by both studies. Historical data was used in this research to internally assess the supply chain, comparing its own results over time. It would be interesting to compare the Sishen-Saldanha supply chain with the Pilbara iron ore supply chain in Australia in future research.

\section{Validity and reliability}

The reliability of the CSCEM was tested by test-retest reliability and alternative-form reliability. The test-retest reliability estimates were obtained by using the CSCEM to analyse the same set of data more than once and analyse another set of generated data. Similar results were obtained from each evaluation, thus proving test-retest reliability. Alternative-form reliability was tested by comparing the

TABLE 4: Port node slacks analysis results.

\begin{tabular}{|c|c|c|c|c|c|c|c|}
\hline Measure & Slack & DMU1 & DMU2 & DMU3 & DMU4 & DMU5 & DMU6 \\
\hline System uptime (R) & $\mathrm{s}_{1}^{-}$ & 17.673 & 4.575 & 15.238 & 21.438 & 25.266 & 39.565 \\
\hline Idle time $(\mathrm{R})$ & $\mathrm{S}_{2}^{-}$ & 0 & 2.297 & 0 & 3.477 & 0 & 0 \\
\hline Utilisation (R) & $\mathrm{S}_{3}^{-}$ & 14.287 & 3.153 & 10.968 & 16.738 & 24.347 & 31.416 \\
\hline Communication links ( $R$ ) & $\mathrm{S}_{4}^{-}$ & 0 & 0 & 0 & 2.098 & 0 & 0 \\
\hline Document errors (R) & $\mathrm{S}_{5}^{-}$ & 4.372 & 2.697 & 0 & 8.567 & 13.452 & 8.747 \\
\hline Extraction cost/ton (C) & $\mathrm{S}_{6}^{-}$ & 5.671 & 1.728 & 4.23 & 14.206 & 15.325 & 11.651 \\
\hline Infrastructure cost (C) & $\mathrm{s}_{7}^{-}$ & 1.521 & 0.344 & 0 & 17.971 & 25.706 & 0 \\
\hline Labour (C) & $\mathrm{S}_{8}^{-}$ & 7.416 & 0 & 11.37 & 1.764 & 0 & 18.137 \\
\hline Communication (C) & $\mathrm{S}_{9}^{-}$ & 6.571 & 2.528 & 6.275 & 29.174 & 33.999 & 11.149 \\
\hline throughput efficiency (R) & $\mathrm{s}_{1}^{+}$ & 7.874 & 2.479 & 6.826 & 10.012 & 13.681 & 17.577 \\
\hline Extraction time (S) & $\mathrm{s}_{2}^{+}$ & 0 & 0 & 0 & 0 & 18.123 & 7.0947 \\
\hline Goods handling efficiency (S) & $\mathrm{S}_{3}^{+}$ & 0 & 0 & 1.841 & 0 & 0 & 0 \\
\hline
\end{tabular}

Source: Goedhals-Gerber, L.L., 2010, The Measurement of Supply Chain Efficiency: Theoretical Considerations and Practical Criteria, PhD dissertation, Stellenbosch University, Stellenbosch 
results obtained by the CSCEM when run through the program written by Gerber (2009) with results obtained when it was run through the well-known computer program DEA-P (2003) as well as a program written for Excel by Naude (2009). Similar results were obtained in all three cases, thus proving alternative-form reliability.

Concurrent validity and content validity were used to test the validity of the CSCEM. The content validity of the CSCEM was proven, because the variables included in the model were chosen based on a literature review as well as interviews conducted with business executives who work with supply chains on a daily basis and are aware of the main problems faced by South African supply chains. Feedback was given to the firms involved in the case study and they agreed with the obtained results, proving the concurrent validity of the CSCEM.

\section{Advantages of the composite supply chain efficiency model}

The CSCEM adds value for a number of reasons. Firstly, the CSCEM was specifically developed for South African, i.e. it includes the factors identified by industry experts that are the main causes of inefficiency along South African supply chains. Secondly, the CSCEM is simple to use and does not require either an advanced degree in mathematics or extended training for employees before it can be implemented by a firm (this is an advantage over the SCOR model, which is currently used as the cross-industry standard for measuring supply chain performance both internationally and in South Africa). Once the data has been collected by a firm or supply chain, the computer program developed by Gerber (2009) can be used to obtain results at the click of a button. Thirdly, it is an inexpensive model and, therefore, can be utilised by small firms with a limited budget (this is another advantage over the SCOR model). Fourth, its generic nature means that it can be used to measure supply chain efficiency across various different types of supply chains. The efficiency results generated by the CSCEM can be used to identify and analyse weaknesses and bottlenecks in supply chains. Fifth, it can either be used to compare different supply chains or it can be used to compare the same supply chain over time to determine whether any improvements have been made. Finally, the CSCEM has the ability to compare individual nodes both separately and as part of an entire supply chain. Therefore, a firm wanting to know how it compares to similar firms will be able to use the CSCEM as well as a firm wanting to determine the most efficient supply chain in a specific sector or industry.

The CSCEM is a simple, systematic and inexpensive model that can be applied to South African supply chains handling a wide variety of products that are either local or export oriented, to determine whether they are operating efficiently or not. The results obtained from the CSCEM are easy to understand and can, therefore, help firms and entire supply chains identify areas to focus on to improve their overall levels of efficiency and in so doing make them more competitive.

\section{Conclusion}

International and local companies are facing an increasingly challenging market position. There are higher levels of competition, higher customer expectations and complex supplier relationships. As the levels of competition and complexity have increased, supply chain management has emerged as an increasingly important issue for all the parties concerned. The challenge of supply chain management is to identify and implement strategies that minimise costs, while maximising flexibility in an increasingly competitive and complex market.

South African supply chains cannot be viewed in isolation. For South African firms to compete globally, they must meet international standards. This can only be achieved if South African firms are aware of how they perform in comparison to international benchmarks. The results show that the CSCEM can be used by South African firms to measure their levels of supply chain efficiency and can therefore provide South African supply chains with the information necessary to identify bottlenecks as well as make recommendations of ways to improve their shortcomings.

The CSCEM is systematic and easy to use. It can be used to measure supply chain efficiency across various types of supply chains due to its generic nature. The CSCEM can be used to compare different supply chains or to determine whether a supply chain's efficiency has improved or deteriorated over time. It can be applied to supply chains handling a wide variety of products that are either local or export oriented, to determine whether they are operating efficiently or not. The results obtained from the CSCEM are easy to understand and can therefore assist South African firms and entire supply chains to identify areas to focus on to improve overall levels of efficiency and in so doing make them more competitive.

\section{Recommendations}

South African firms need to comprehend the significance of evaluating their performance and determining their efficiency levels. Without acknowledgement of this fact, South African firms are going to continue to miss the opportunity of gathering valuable information about their operations and learning from their mistakes.

South African firms need to become more vertically integrated along a supply chain. The supply chain used in the case study of this article is made up by both public (Transnet Freight Rail, Transnet National Ports Authority and Transnet Port Terminals) and private enterprises (Kumba Resources Ltd and Associated Manganese (ASSMANG) iron ore mine and Kumba Port Operations Saldanha); each of which strive for different objectives. Private firms strive to maximise 
profit, while public firms take social costs into account as well. For South African supply chains to be competitive internationally, all firms along a supply chain will have to agree on and strive towards the same objectives.

\section{Future work}

The supply chain used in the case study of this article was only assessed internally through the use of historical data. It would be interesting to be able to compare the SishenSaldanha iron ore supply chain with the Pilbara iron ore supply chain in Australia. The Pilbara iron ore supply chain is the benchmark for iron ore supply chains in the world. It exported 439.6 Mt of iron ore between January and June 2015 (Validakis 2015), compared to the $23.2 \mathrm{Mt}$ exported along the Sishen-Saldanha iron ore supply chain (AngloAmerican 2015). A comparison between the Sishen-Saldanha iron ore supply chain and the Pilbara iron ore supply chain would provide a true reflection of just how efficient the SishenSladanha iron ore supply chain really is.

\section{Acknowledgements Competing interests}

The author declares that she has no financial or personal relationships which may have inappropriately influenced her in writing this article.

\section{References}

Abu-Suleiman, A., Boardman, B. \& Priest, J.W., 2004, A framework for an integrated supply chain performance management system, viewed 08 March 2013, from http://www.iienet.org/files/443.pdf

Agami, N., Saleh, M. \& Rasmy, M., 2012, 'Supply chain performance measurement approaches: Review and classification', Journal of Organizational Management Studies 2012, Article ID 872753, 20 pages, http://dx.doi.org/10.5171/2012.872753

AngloAmerican, 2015, Kumba Iron Ore Limited interim results for the six month ended June 2015, viewed 22 October 2015, from http://southafrica.angloamerican.com/ media/press-releases/2015/21-07-2015.aspx

Awad, H.A.H. \& Nassar, M.O., 2010, 'A broader view of the supply chain integration challenges', International Journal of Innovation, Management and Technology $1(1), 51-56$

Badr, Y. \& Stephan, J., 2007, 'Security and risk management in supply chains', Journal of Information Assurance and Security 2, 288-296.

Banker, R., Charnes, A. \& Cooper, W., 1984, 'Some models for estimating technical scale inefficiencies in data envelopment analysis', Management Science 30(9), 1078-1092.

Barloworld Logistics, 2005, Supply chain foresight 2005, viewed 10 June 2010 from http://www.barloworld-logistics.com/wp-content/uploads/2013/11/ Supplychainforesight-Report-2005.pdf

Bell, R. \& Morey, R., 1995, 'Increasing the efficiency of corporate travel management through macro Benchmarking', Journal of Travel Research 33(3), 11-20.

Braithwaite, A., 2005, 'Maximising performance: The power of supply chain collaboration', viewed 10 June 2015, from http://www.cefic.org/Documents/ IndustrySupport/Transport-and-Logistics/Maximising-performance-the-powerof-supply-chain-collaboration-October2005.pdf

Chandra, C. \& Grabis, J., 2007, Supply chain configuration: Concepts, solutions, and applications, Springer Science and Business Media, New York.

Charnes, A., Cooper, W.W. \& Rhodes, E., 1978, 'Measuring the efficiency of decision making units', European Journal of Operational Research 2, 429-444.

Chasomeris, M., 2005, South Africa's maritime policy and transformation of the shipping industry, viewed 17 June 2008, from http://www.essa.org.za/ download/2005Conference/Chasomeris.pdf

Chen, W.-P., Chung, H., Ho, K.-Y. \& Hsu, T.-L., 2008, 'Portfolio optimization models and mean variance spanning tests', viewed 14 August 2014, from http://www. centerforpbbefr.rutgers.edu/Jan11-2008\%20papers/7-2.doc

Childerhouse, P. \& Towill, D., 2000, 'Engineering supply chains to match customer requirements', Logistics Information Management 13(6), 337-346.
Chiu, K., 2014, 'Worldwide: Analysis of the economic development prospects of BRICS countries', viewed 01 October 2015, from http://www.mondaq.com/
southafrica/x/330536/international+trade+investment/Analysis+Of+The+Econo southafrica/x/330536/international+trade+investm
mic+Development+Prospects+Of+BRICS+Countries

Chopra, S. \& Sodhi, M.S., 2014, 'Reducing the risk of supply chain disruptions', viewed on 12 June 2015, from http://sloanreview.mit.edu/article/reducing-the-risk-ofsupply-chain-disruptions/

Christopher, M., 1998, Logistics and supply chain management: Strategies for reducing costs and improving services, 2nd edn., Financial Times/Pitman Publishing, London.

Cooper, W., Seiford, L. \& Zhu, J., 2004, Handbook on data envelopment analysis, Kluwer Academic Publisher, Boston, MA.

Council for Supply Chain Management Professionals, 2015, CSCMP supply chain management, viewed 14 July 2015, from https://cscmp.org/about-us/supplychain-management-definitions

Cuthbertson, R. \& Piotrowicz, W., 2011, 'Performance measurement systems in supply chains: A framework for contextual analysis', International Journal of Productivity and Performance Management 60(6), 583-602.

Davis, E.W. \& Spekman, R.E., 2004, Extended enterprise: Gaining competitive advantage through collaborative supply chains, Prentice Hall, Upper Saddle River, NJ.

Davis, T., 1993, Effective supply chain management, viewed 14 June 2015, from http:// sloanreview.mit.edu/article/effective-supply-chain-management/

DEA-P, 2003, A data envelopment analysis (computer) program, viewed 01 May 2009, from http://www.uq.edu.au/economics/cepa/deap.htm

Department of Government Communications and Information Systems, 2015, Economic sectors, employment \& infrastructure development cluster post SoNA media briefing, viewed 22 October 2015, from http://www.gcis.gov.za/newsroom/media-releases/ economic-sectors-employment-infrastructure-development-cluster-post-sona

Dooley, F., 2005, Logistics, inventory control, and supply chain management, viewed 15 July 2015, from http://www.choicesmagazine.org/2005-4/supplychain/2005-4-14. htm

Emrouznejad, A., 1995-2001, Ali Emrouznejad's DEA HomePage, Warwick Business School, Coventry, UK.

Everatt, D., 2004, The politics of poverty, viewed 23 April 2014, from http://us-cdn creamermedia.co.za/assets/articles/attachments/01013_politicsofpoverty.pdf

Ferrier, G. \& Lovell, C., 1990, 'Measuring cost efficiency in banking: Econometric and linear programming evidence', Journal of Econometrics 46(1), 229-245.

Forbes.com, 2006, Logistics glossary, viewed 20 March 2014, from http://www. forbes.com/fdc/logistics/glossary_d.shtml

Gerber, H.R., 2009, Supply chain efficiency analysis program.

Goedhals-Gerber, L.L., 2010, The Measurement of Supply Chain Efficiency: Theoretical Considerations and Practical Criteria, PhD dissertation, Stellenbosch University, Stellenbosch.

Granite Financial Group, 2009, Glossary, viewed 03 June 2009, from http://www. mainstreetfinancialgrp.com/index.cfm?skipsplash=1

Gunasekaran, A., Patel, C. \& McGaughey, R.E., 2004, 'A framework for supply chain performance measurement', International Journal of Production Economics 87(3), 333-347.

Heaney, B., 2013, Supply chain visibility: A critical strategy to optimise costs and service, viewed 10 June 2015, from http://www.gs1.org/docs/visibility/Supply_ Chain_Visibility_Aberdeen_Report.pdf

Holmberg, S., 2000, 'A systems perspective on supply chain measurements', International Journal of Physical Distribution \& Logistics Management 30(10), 847-868.

Huan, S.H., Sheoran, S.K. \& Wang, G., 2004, A review and analysis of supply chain operations reference (SCOR) model, viewed 17 March 2014, from http:// www.emeraldinsight.com/Insight/ViewContentServlet?Filename=Published/ EmeraldFullTextArticle/Articles/1770090103.html

Ittmann, H.W., 2007, 'Introduction', in H.W. Ittmann, C. Schoeman, D.J. King, A.H. Naude, E.N. Ralehoko, I.A. Meyer, et al., The Third Annual State of Logistics Survey for South Africa 2006, pp. 2-3, CSIR, Pretoria, South Africa.

Joseph, S.J. \& Mohapatra, S., 2009, Management information systems in knowledge economy, PHI Learning Private Limited, New Delhi.

Kussing, U.I., 2009, 'Controlling logistics performance', in W.J. Pienaar \& J.J. Vogt, Business logistics management, 3rd edn., pp. 438-459, Oxford University Press, Cape Town, Southern Africa.

Langfield-Smith, K. \& Smith, D., 2005, 'Performance measures in supply chains', Australian Accounting Review 15(35), 39-51.

Little, A.D., 1999, A European supply chain survey, viewed 31 October 2005, from http://www.adlittle.be/insights/studies/pdf/european_supply_chain_survey.pdf

Lee, H.L., 2000, Creating value through supply chain integration, viewed 07 March 2014, from http://www.manufacturing.net/?layout=articlePortal_V2 \&\&articleid=CA1 $51843 \backslash \&$ search=webexclusive $\backslash \&$ text=creating+value+through+supply+chain+ integration

Mkhwanazi, X., 2012, 'Skills development vital to SA's economic growth', Chairman of BHP Billiton, who was speaking at the 4th annual BHP Billiton Skills Development Summit held in Tshwane on Wednesday, July 25, 2012, viewed 12 March 2015 from http://www.bbqonline.co.za/articles/media-release.48-1272.html

Morita, H., Hirokawa, K. \& Zhu, J., 2005, 'A slack-based measure of efficiency in context-dependent data envelopment analysis', Omega: The International Journal of Management Science 33, 357-362. 
Naslund, D. \& Williamson, S., 2010, 'What is management in supply chain management? - A critical review of definitions, frameworks and terminology', Journal of Management Policy and Practice 11(4), 11-28.

Naude, J., 2009, The dairy dea model excel solver, Honours Research, Department of logistics, University of Stellenbosch.

Neely, A., Gregory, M. \& Platts, M., 1995, Performance measurement system design: A literature review and research agenda, viewed 28 November 2014, from http:// www.emeraldinsight.com/Insight/?Filename=Published/EmeraldFullTextArticle/ Articles/0240150405.html

Neill, L., 2003, 'State commits additional R17,5 bn to speed up logistics chain', Freight and Trade Weekly, 15 August 2003, p.4.

Nigel Wright Group, 2015, Supply chain best practice - Sector specific or transferable? viewed 10 July 2015, from http://www.nigelwright.com/knowledge-centre/news/ vipply-chain-best-practice-sector-specific-or-transferable/

Nkomo, J.C., 2005, Energy and economic development: Challenges for South Africa, viewed 03 October 2015, from http://www.erc.uct.ac.za/jesa/volume16/163jesa-nkomo.pdf

Page, J., 2012, 'Can Africa industrialise?', Journal of African Economies 21(AERC Suppl 2), ii86-ii125, http://dx.doi.org/10.1093/jae/ejr045

R 2.9.2, 2009, viewed on from http://lib.stat.cmu.edu/R/CRAN/

Sadler, I., 2007, Logistics and supply chain integration, Sage Publications, London.

Samuel, H.H., Sunl, K.S. \& Wang, G., 2004, 'A review and analysis of supply chain operations reference (SCOR) model', Supply Chain Management: An International Journal 9(1), 23-29.

Seiford, L., 1994, 'Data envelopment analysis: The evolution of the state of the art (1978-1995)', Journal of Productivity Analysis 7(2-3), 99-137.
Spekman, R.S., Salmonds, D. \& Kamauff, J., 1994, 'At last procurement becomes strategic', Long-Range Planning 31(4), 75-81.

Statistics South Africa, 2015, 'More South Africans living in poverty', viewed 03 October 2015, http://www.news24.com/Archives/City-Press/More-SouthAfricans-living-in-poverty-Stats-SA-20150429

Talluri, S. \& Sarkis, J., 2001, 'A computational geometry approach for benchmarking', International Journal of Operations \& Production Management 21(1), 210-222.

The World Bank, 2014, 'Export competitiveness, regional trade integration could Spur South African Export Growth', viewed 02 October 2015, from http://www. worldbank.org/en/country/southafrica/publication/south-africa-economicupdate-focus-export-competitiveness

Trkman, P., Indihar Stemberger, M. \& Jaklic, J., 2005, Information transfer in supply chain management, viewed 23 October 2014, from http://2005papers.iisit.org/ 146f91Trkm.pdf

Truter, C., 2004, Route 27 West coast South Africa: The Sishen-Saldanha railway line, viewed 10 April 2006, from http://www.route27sa.com/sishen.html

University of Phoenix, 1996, 'Data envelopment analysis', viewed 08 May 2008, from http://www.emp.pdx.edu.edu/dea/wvdea.html

Validakis, V., 2015, Iron ore export levels out of the Pilbara explode, viewed 22 October 2015, from http://www.australianmining.com.au/news/iron-ore-export-levelsout-of-the-pilbara-expl-1

Van der Laan, J., 2010, 'Supply chain integration', viewed 02 October 2015, from http://retaileconomics.com/supply-chain-integration/

Wong, W. \& Wong, K., 2007, 'Supply chain performance measurement system using DEA modeling', Industrial Management \& Data Systems 107(3), 361-381.

Wong, W. \& Wong, K., 2008, 'A review on benchmarking of supply chain performance measures', Benchmarking: An International Journal 15(1), 25-51. 